\title{
BOOK REVIEWS / CRITIQUES DE LIVRES
}

Ian Marsh, John Cochrane, and Gaynor Melville. (2004). Criminal Justice: An Introduction to Philosophies, Theories and Practice. London: Routledge. Pp. 248. ISBN 978-0415333009

Criminal Justice: An Introduction to Philosophies, Theories and Practice helps students to develop a deeper understanding of the context and current functions of the criminal justice system (CJS). The first part of the book provides a comprehensive and clear analysis of the main philosophical aims and sociological theories of punishment, historical context of punishment and justice, and the evolving perspective of victimology. The second part focuses on the key players in the current CJS, such as the police, courts, and judiciary. There are reflective questions that occur throughout the text, which allow students to critically respond to information presented in the text. The book is very detailed and its intensive revision of the CJS is highly useful. The book conveys knowledge about the CJS in seven differentiated chapters, which are easily manageable and locatable. It also discusses information about the vital issues of the CJS and its legal responsibilities; the legalised, political, and social context in which they operate. Also, the book highlights issues surrounding the criminal law and discusses how different types ofcrime and deviance are portrayed. The text examines how the non-legal aspects of criminal justice impacts the aims and objectives of the CJS and influences certain policies.

The key issues include the operation of the police; the necessity of probation/probation officers; the role of prisons; the magistrates/crown prosecution courts, and the service of the crown prosecution. These elements of the CJS are important to discuss as they impact the construction of criminal appeals and the responsibility of the home office. Furthermore, the police, probation and magistrates directly affect changes of the criminal case review commission, which affects the co-operation of the parole board. Meanwhile, the CJS attempts to break through this barrier and tries to prevent delinquent behaviour from occurring.

There is one particular recurring aspect that is unclear in this book; that is, the unspecified definition of the 'criminal justice system'. Although the authors do make clear the roles of solicitors, barristers, and judges etc, it is ambiguous as to whether or not the definition of the 'criminal justice system' includes the penal system, legislation, jury pool, and prisons conceptualised under such a heading. It was hoped that the whole definition of the CJS would be easily understandable and clear; therefore, for future reference, definitions should be clearer and concise.

Fundamentally, the first chapter suggests three main components: deterrence, retribution, and rehabilitation. These concepts often contradict and overlap with one another, but they interlink with why punishment should be active in comparison to chapter two, which focuses on theories of punishment (based around Durkheim, Marxist, Weber and Foucault's point of view). In contrast, chapter three presents evidence of the history side of prisons and crime, and again involves theoretical approaches as mentioned above - it tries to correlate this with history. While chapter four conveys information surrounding victimology, which explains who is most likely to be the victim and offender, the chapter also illustrates theories and pays great attention to domestic violence. Further, it compares and contrasts conventional crimes with corporate crimes. Chapter five details police and policing and gives a brief outline of the main social groups that comprised the early police force. Chapter six focuses on the courts, sentencing, and judiciary. Similarly to chapter five, social groups are introduced in this section and are used to discuss the 'chivalry thesis' (that is, claims that women will be treated more leniently for committing certain 
crimes) and how social groups affect sentencing. Finally, chapter seven consists of the prisons and imprisonment aspects, which shows that the prison population is increasing, and conveys different types of sentencing.

Above all, each chapter includes a 'further reading section' and various review questions. The book outlines a chronology of key dates and has an assortment of websites and a glossary of helpful terms. In order to illustrate these points, the book contributes some of its awareness on meticulous criminal cases, such as The Strange Ways Riot and The Background to the Woolf Report, as well as many others like the 'Bloody Mary' to 'Moral Panics and Folk Devils'. However, the book describes such cases with valuable summaries of their circumstances.

The authors believe the CJS has undergone a radical transformation and postulate the need for a restorative justice approach to deal with the most pressed issues within the system. . The initial assumption of this development is not only to reform the CJS, but also to implement and improve the efficiency of people's daily lives and the legal system; coinciding with the way we do justice in our society. Equally, it conveys rationality in the sense that it 'opens our eyes' and enables society to empathize with the whole CJS and the threads that underpin it.

Summarising the book as a whole, it concomitantly consists of information about the CJS being the fundamentals of a flourishing and cultured society. It develops points about the service of the police and the necessity of the legal system. It also points out that the CJS is not futile; rather it is a vital agency that allows society to continue its cycle. Conversely, people's culture is threatened by crime and deviance, and this book clarifies that change is an essential component that will guard society; accomplished by legislations and agencies. Importantly, the book theorises that society cannot do anything about crime/deviance and the system. Chapters 1, 3, 4, 5 and 6 in particular help our understanding of the CJS, because we can compare and contrast how the process was 'back in the day' to contemporary society, so changes can be observed and understood.

Significantly, the book contributes to an understanding of criminology and the CJS by outlining the progress the CJS has made and focussing on means of deterrence and preventing recidivism In addition, the book indispensably states that all types of crime should be tackled, especially minor crimes because more time and effort can be put into dealing with repeat offenders and violent crime. Nonetheless, from this book, it seems crime is declining and more offences are being brought to justice.

Although some of the chapters conducted are ambivalent, especially those containing historical references, the authors have structured the chapters clearly and logically. However, the historic chapters felt repetitive and were rather forceful in expressing the main points. Nevertheless, on the whole, the book is a gripping and controversial read, and the reviewer recommends students to at least examine the fundamental argument of the book. Due to its history-oriented content, this book would undoubtedly be favoured by a university history studies programme or showcased in the history section of most libraries. At the same time, libraries that support programs, such as law, media and perhaps journalism ought to acknowledge this book, since it touches on areas within law and media.

To provide a richer and deeper understanding on some of the issues that the book leaves out, I recommend that readers of this book peruse Prison Readings: A Critical Introduction to Prisons and Imprisonment by Jewkes and Johnston (2006), as this book provides a detailed description and evaluation of the historical progress regarding the CJS, which Marsh et al lacks. Readers should also consider Victims, crime and society by Davies et al (2007), which covers more about how victims are treated within the CJS. Marsh et al lacks great detail about how 
victimology is construed within the CJS, but Davies et al gives a very detailed and sufficient account of crime victims and the CJS collectively.

\author{
Reviewed by Aliraza Javaid \\ York University
}

\title{
References
}

Davies, P., Francis, P., and Greer, C. (2007) (eds.) Victims, crime and society. London: Sage.

Jukes, Y., and Johnston, H. (2006). Prison Readings: A Critical Introduction to Prisons and Imprisonment. USA and Canada: Willan Publishing. 
Robert Chrismas (2013). Canadian Policing in the 21 ${ }^{\text {st }}$ Century: A Frontline Officer on Challenges and Changes. Montreal and Kingston: McGill-Queen's University Press. Pp. 322: ISBN 9780773542747.

Robert Chrismas' Canadian Policing in the $21^{\text {st }}$ Century: A Frontline Officer on Challenges and Changes offers a rare perspective of policing in Canada. As a frontline officer with 28 years of experience with the Winnipeg Police Service and a doctoral candidate in peace and conflict studies, Chrismas' book offers information that is not only valuable to researchers, but interesting to those outside the academic community as well. It covers a wide range of policing-related topics including the history of law enforcement in Canada, how the roles and experiences of police officers have changed over the years, current successes and continued challenges within Canadian policing as well as suggestions for potential improvements for the future. The book is enriched by stories of Chrismas' own experiences as a police officer. These personal anecdotes help to not only reinforce his arguments but provide the reader with a unique look into the various challenges faced by front-line officers, such as dealing with an individual attempting to commit 'suicide-by-cop'. Chrismas' experience and dedication to improving the effectiveness of policing in Canada is explicitly evident throughout the book, which is broken up into eleven chapters.

The beginning of the book outlines Chrismas' background as a police officer and sets the stage for his discussion of policing in the $21^{\text {st }}$ century. In the first chapter he provides a brief summary of the history of policing in Canada followed by a description of the current situation. This ensures that all readers have a frame of reference when it comes to current policing and a basic understanding of the structure of law enforcement in Canada. From this point, the chapters are broken up into various police-related topics.

In chapter 2, Chrismas discusses financial aspects of the justice system. He highlights the challenges associated with different costs and resource-allocation within police departments and offers recommendations to minimize many of these issues. In addition, he discusses the movement toward privatization of security in Canada and resulting benefits and challenges associated with this trend.

Within chapters $3,4,5$ and 6 Chrismas highlights multiple aspects of policing that have changed over the years. First, in chapter 3 he discusses the greater expectations faced by police officers as a result of higher standards and stricter rules as well as an increase in overall caseloads. In addition, in Chapter 4 he emphasizes that while improvements in technology have resulted in more effective equipment for law enforcement, these same advances have simultaneously allowed criminals and their crimes to become more sophisticated. He then goes on to discuss in Chapter 5 how these changes have resulted in differences between experienced officers and those who are new to the force and emphasizes the importance of finding common ground and developing good communication to prevent "intergenerational issues" (p. 100). Finally, in Chapter 6, Chrismas discusses the increasing number of post-secondary degrees and other credentials held by new recruits. At the same time, he highlights the value of real life experience and the importance of having these individuals train with and be mentored by seasoned officers.

Chapters 7 and 8 focus on topics related to policing and Aboriginals as well other minority groups in Canada. First, Chrismas emphasizes the importance of having all members of the public view the police as fair and trustworthy, regardless of race or ethnicity. Thus, he reiterates the importance of developing cultural sensitivity as well as hiring officers from multiple backgrounds. In Chapter 8, he further discusses this with respect to other races and women. $\mathrm{He}$ 
argues that police forces need to continue to work to improve relations with all groups. In addition, he highlights the past and present challenges faced by female officers as well as the improvements that have been, and should be made to increase equality and enhance their overall experience.

In Chapter 9, Chrismas outlines differences and shifts in accountability across levels of governance. He highlights challenges associated with funding across these different groups when it comes to large-scale crises like natural disasters and the terrorist attacks of 9/11. Thus, he emphasizes the importance of communication and cooperation from all levels of government, as well as private and public sector agencies when it comes to dealing with these issues.

In Chapters 10 and 11, Chrismas discusses the importance of transparency and accountability on the part of police to generate and maintain public trust. At the same time, he highlights that the expectation placed on officers to maintain their professionalism can be challenging as they are often faced with situations that are highly dangerous and stressful. He argues that despite hesitation toward certain changes, such as video-taped interviews, these alterations are beneficial as they serve to increase transparency and public confidence in the police.

Finally, Chrismas emphasizes the importance of collaboration between law enforcement and the community with respect to reducing crime. He quotes Peel's $7^{\text {th }}$ principle: "the police are the people and the people are the police" (p.247) and states that everyone has a responsibility to ensure public safety. He concludes by arguing that the changes discussed throughout the book have simply altered the battleground and weapons used to fight against evil, but have not eliminated it. Thus, continued reflection is needed to learn from the past and ensure improvements in the future.

Canadian Policing in the $21^{\text {st }}$ Century: A Frontline Officer on Challenges and Changes is an enjoyable and informative read for individuals interested in learning about policing in Canada. It is well-written and avoids the use of heavy jargon, allowing it to be appreciated by a broad audience. In addition, the list of abbreviations offered at the beginning of the book serve as a valuable reference tool. From a criminological perspective, it lacks a theoretical aspect; however, this likely contributes to the book's appeal to a wider audience. In addition, the book's well-sourced information as well as Chrismas' personal stories would certainly serve as valuable information within scholarly projects and could easily be used in conjunction with theoretical work. Thus, not only has Chrismas developed an excellent academic resource, he has provided the public with an understanding and appreciation of what police officers experience while working on the frontlines. 